\title{
Damage to the Median and Ulnar Nerves After a Snake Bite
}

\author{
Giampietro Zanette, Matteo Francesco Lauriola, Stefano Tamburin
}

Key words: Electromyography (EMG), neuropathy, peripheral neuropathy, tropical, ultrasound.

doi:10.1017/cjn.2015.275

Can J Neurol Sci. 2015; 42: 448-449

About 5 million people are bitten by snakes every year, resulting in more than 2 million cases of envenoming and 20,000-125,000 deaths. Most of these cases occur in Asia, Africa, South America, and the Indo Pacific. Muscle weakness caused by pre- or postsynaptic toxins acting on the neuromuscular junction and rhabdomyolysis and ischemic or hemorrhagic strokes are the most common neurological complications of snake bite. ${ }^{1,2}$ Local signs of envenomation are more prominent after viper and colubrid bites, but may also occur in cases of elapid bites and include swelling, blister formation, and necrosis of the skin and subcutaneous tissue. ${ }^{1}$ Peripheral nerve damage is a rare complication of snake bite. ${ }^{3}$ Neuroma-in-continuity represents one of the worst complications of peripheral nerve lesions because of pain and poor recovery. ${ }^{4}$ We report a case of median and ulnar nerve necrosis leading to ultrasound feature of a double neuroma-incontinuity after cobra snakebite to the forearm.

\section{Case Report}

A 26-year-old woman was bitten by a spectacled cobra (Naja $n a j a)$ in the right forearm in Punjab, India. Immediately after the bite, she developed systemic sign of envenomation (bilateral ptosis, muscle weakness, impaired consciousness) and was treated with systemic antivenin and 24 hours of intensive care unit monitoring with good recovery. She also reported complete loss of sensation and force in the right hand immediately after the bite. At the site of snake bite, she presented local signs of envenomation that led to severe necrosis and was treated with surgical desloughing of the necrotic area and subsequent graft of a musculocutaneous flap (Figure 1A). There was some forearm edema, but it was not marked. Four months later, clinical examination showed severe muscle weakness and anesthesia, including burns resulting from marked pain sensory loss, in the areas of the right median and ulnar nerves distal to the musculocutaneous flap. Pressure over the proximal side of the musculocutaneous flap in the sites of median and ulnar nerves evoked shocklike pain. Electrodiagnostic testing documented complete sensorimotor damage of the two nerves. An ultrasound scan showed enlargement of the median and ulnar nerves, suggesting the presence of two neuromas-in-continuity, under the proximal part of the musculocutaneous flap (Figure 1B, C). At the 1-year follow-up, electrodiagnostic testing documented complete sensorimotor damage of the median nerve, but some degree of reinnervation and the reappearance of compound muscle action potential in ulnar-innervated hand muscles. The patient gave her consent for publication of the present case report.

\section{DiscuSSION}

To the best of our knowledge, this is the first report of peripheral nerve focal damage secondary to local effects of snakebite. The Naja species belong to the Elapidae family, and their venom mainly causes systemic effects, but local signs may be prominent in some cases. ${ }^{1,2}$ Cytotoxic enzymes activate pro-inflammatory mechanisms that cause edema, blister formation, and local tissue necrosis. In the present case, nerve trunk necrosis seems the most likely reason for median and ulnar nerve damage, because symptoms appeared immediately after the bite and edema was not marked. However, coexistent compartmental syndrome, which has been reported as a cause of nerve damage after a snake bite ${ }^{3}$ cannot be completely ruled out. ${ }^{1}$ Ischemic damage secondary to surgery appears unlikely because the patient reported symptoms of median and ulnar nerve damage before the musculocutaneous flap graft.

Neuroma is caused by the disorganized growth of nerve fascicles after peripheral nerve trunk damage and is associated with poor outcome, but there is no consensus on its surgical treatment. ${ }^{3}$ Nerve damage and neuroma-in-continuity can be easily and noninvasively documented with an ultrasound scan, which is an emerging technique for diagnosing peripheral nerve damage. $^{5}$

\section{Disclosures}

None.

\section{REFERENCES}

1. Kularatne SA, Budagoda BD, Gawarammana IB, Kularatne WK. Epidemiology, clinical profile and management issues of cobra (Naja naja) bites in Sri Lanka: first authenticated case series. Trans R Soc Trop Med Hyg. 2009;103:924-30.

2. Keith J, White J, Pascu O, Faian V, Keith J. Fatal cerebellar hemorrhage following Australian brown snake envenomation. Can J Neurol Sci. 2012;39:120-1.

3. Hardy DL Sr, Zamudio KR. Compartment syndrome, fasciotomy, and neuropathy after a rattlesnake envenomation: aspects of monitoring and diagnosis. Wilderness Environ Med. 2006;17:36-40.

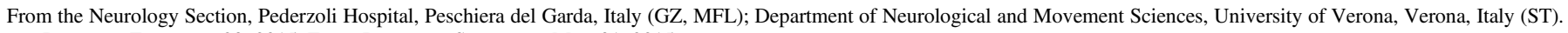
Received February 23, 2015. Final Revisions Submitted May 31, 2015.

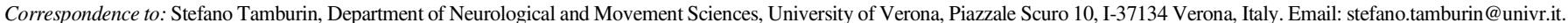



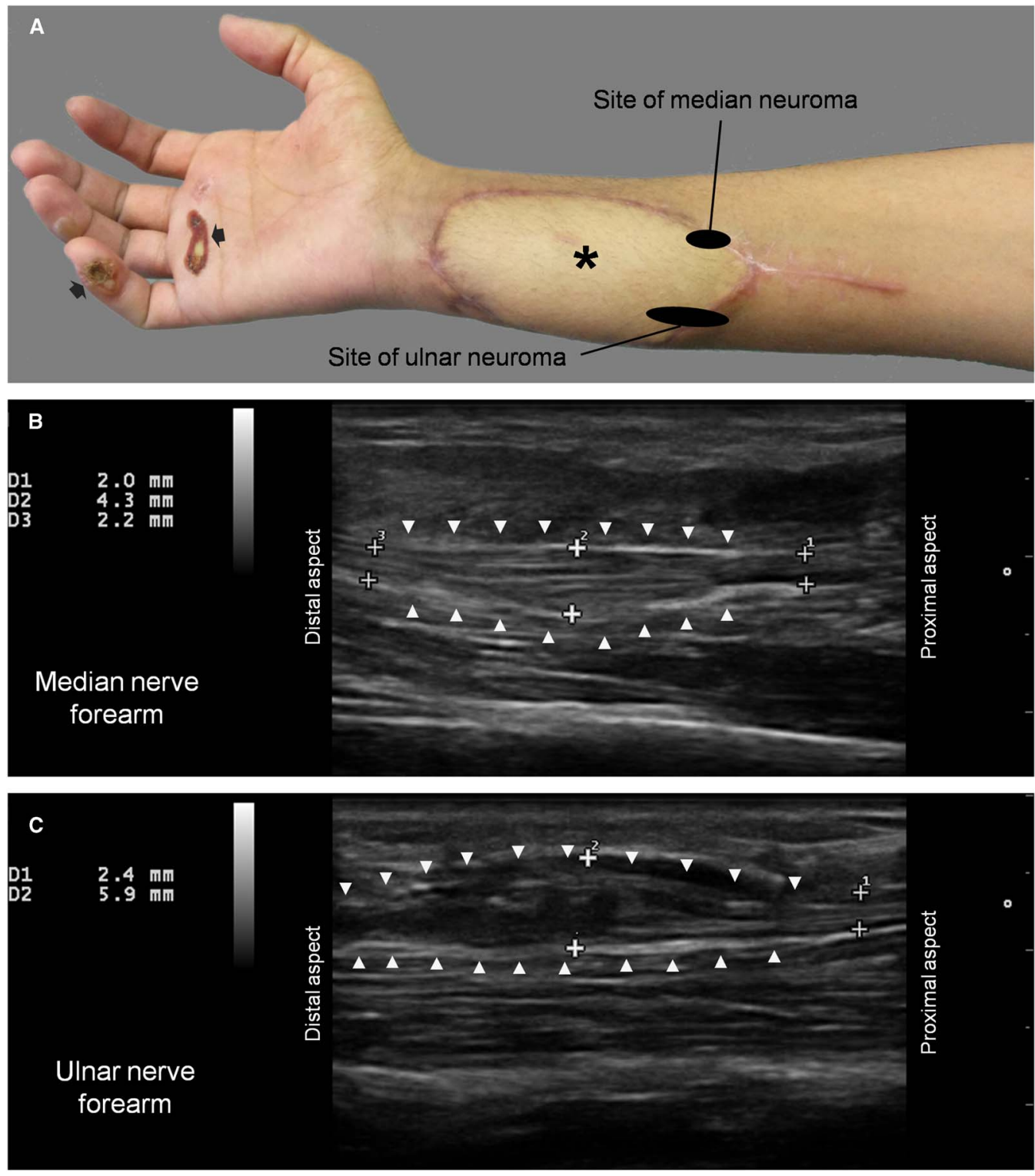

Figure 1: (A) The patient's right upper limb with the musculocutaneous flap (*) and two burns (black arrows) secondary to complete hand anesthesia. $(B, C)$ Ultrasound scan showed enlargement of the median and ulnar nerves, suggesting the presence of two neuromas-in-continuity (white arrowheads) involving the median $(B$, length: $17.1 \mathrm{~mm})$ and ulnar $(C$, length: $36.7 \mathrm{~mm})$ nerves, respectively. Neuroma sites are marked by black oval shapes (A).

4. Hazari A, Elliot D. Treatment of end-neuromas, neuromas-incontinuity and scarred nerves of the digits by proximal relocation. J Hand Surg Br. 2004;29:338-50.
5. Peer S, Harpf C, Willeit J, Piza-Katzer H, Bodner G. Sonographic evaluation of primary peripheral nerve repair. J Ultrasound Med. 2003;22:1317-22. 